\title{
Analysis of the mechanical composite properties of ii-chamber variations in the closed injection pultrusion process
}

\author{
Sebastian Strauß, Simon Boysen, Andreas Senz, Frederik Wilhelm and Niko Rilli
}

Sebastian Strauß. Fraunhofer Institut für Gießerei-, Composite- und Verarbeitungstechnik IGCV, Am Technologiezentrum 2, 86159 Augsburg, Deutschland.

Corresponding author: sebastian.strauss@igcv.fraunhofer.de

Simon Boysen. Fraunhofer Institut für Gießerei-, Composite- und Verarbeitungstechnik IGCV, Am Technologiezentrum 2, 86159 Augsburg, Deutschland.

Andreas Senz. Fraunhofer Institut für Gießerei-, Composite- und Verarbeitungstechnik IGCV, Am Technologiezentrum 2, 86159 Augsburg, Deutschland.

Frederik Wilhelm. Fraunhofer Institut für Gießerei-, Composite- und Verarbeitungstechnik IGCV, Am Technologiezentrum 2, 86159 Augsburg, Deutschland.

Niko Rilli. Fraunhofer Institut für Gießerei-, Composite- und Verarbeitungstechnik IGCV, Am Technologiezentrum 2, 86159 Augsburg, Deutschland.

Abstract. Pultrusion is an established and efficient process for producing continuous fiber-reinforced composites. The resin systems that are currently most frequently used are unsaturated polyesters and vinylesters. These have a long pot life, are well known, and have good processing properties. Highly reactive resins such as polyurethane (PU) and amine hardening epoxy have been in use for a few years. These resin classes are remarkable for their extended range of properties. This opens up new application fields for pultrusion technology but poses challenges for the processing technology. Short pot lives of just a few minutes require a modified process: closed injection pultrusion (CIP). Various approaches about the design and layout of the internal geometry of the injection and impregnation chambers (ii-chamber) are the subject of ongoing research. Numerous parameters influence the impregnation process in the ii-chamber and the quality of the resulting composite. In this study, two innovative, highly reactive resins for use in the pultrusion process were analyzed, both resins based on aliphatic polyurethanes. In phase 1 of the experiments, a commercial aliphatic polyurethane-system for pultrusion applications was used. In Phase 2, the recently developed biobased aliphatic polyurethane-system for pultrusion applications was used for the study's main experiments. The aim of the study was to analyze the material and processing properties with various modifications of the impregnation setup. Therefore, a newly developed ii-chamber and die were tested. The ii-chamber was designed to enable easy adjustment of some of the main influencing parameters during the pultrusion process. A test strategy was developed to evaluate the properties of the composites. An assessment of the influence of the process- and die-based parameters should enable an evaluation of the optimal processing settings by analysis of the material characteristics. The most significant effect of variations in the pultrusion process was found in the interlaminar shear strength (ILSS). ILSS was analyzed for all process variations for both resin systems.

Keywords. Pultrusion, Closed Injection Pultrusion, Thermoset, Injection and Impregnation Chamber, Polyurethane

\section{Introduction}

Pultrusion is an established technology for the continuous production of fiber-reinforced composites. The process can be used to produce profiles with a constant cross-section, such as flat, round, or hollow profiles $[1,2]$. The advantages of the process include high process efficiency, the use of low-cost raw materials, high fiber volume fractions, good surface qualities of the laminates, and less complex plant technology [3, 4, 5]. 
Analysis of the mechanical composite properties of ii-chamber variations in the closed ...

The basic thermosetting pultrusion process is shown in Fig. 1 and can be divided into four steps. At the beginning of the process, the fibers and textiles (1) to be used are provided. Here, the fiber material is fed to the process from creels and preformed via guide plates. Then impregnation (2) of the fibers with the resin system takes place. Depending on the selected resin system, this can be implemented by an open bath (OB) or a Closed Injection Pultrusion. In the next step, the impregnated fibers are drawn through a heated die where shaping and curing (3) takes place. In the final step, the laminate is continuously pulled and cut $(4)[1,3]$.

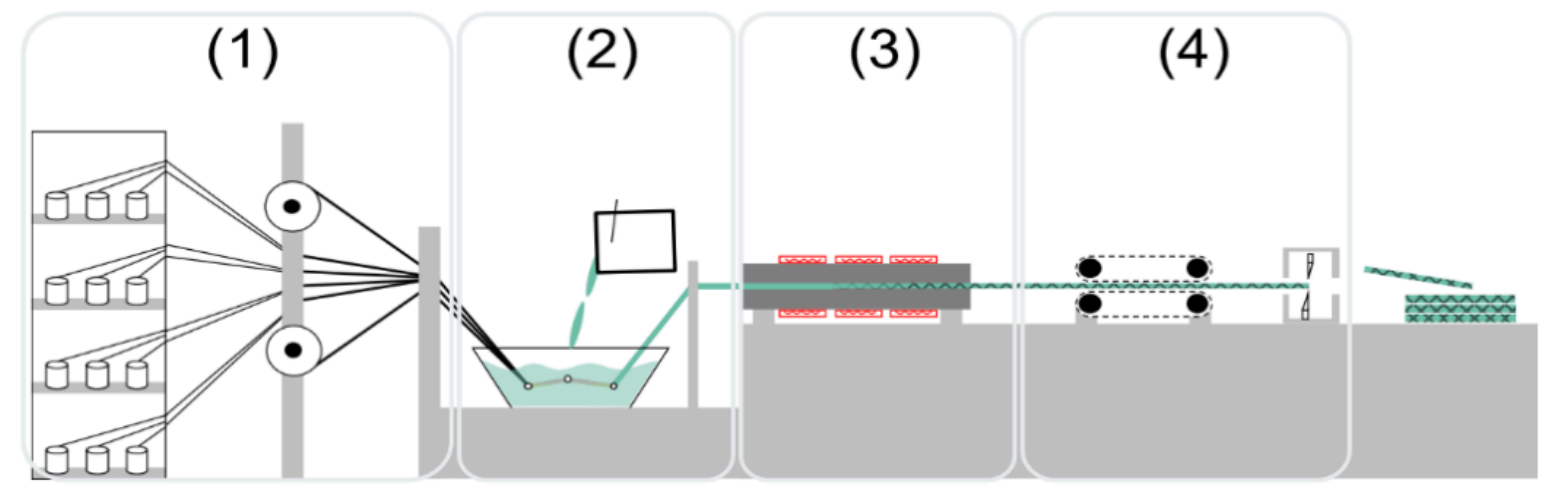

Figure 1: Schematic principle of pultrusion [26]: (1) roving and textile storage and transport with preforming, (2) impregnation, (3) curing in the pultrusion die, (4) pulling, cutting and packaging

Thermoset resin systems such as unsaturated polyesters or vinylesters are the main systems used in pultrusion [6, 3]. Long pot life allows processing in an OB impregnation, see Fig. 1. Good processing properties and many years of experience regarding their use are further advantages of these conventional resin systems [3]. However, their processing in an $\mathrm{OB}$ impregnation also has disadvantages: increased waste volume and material loss, high cleaning costs, and the emission of volatile organic compounds, which have a negative impact on both: the workers and the environment, are worthy of mention here $[5,7,8]$.

CIP was developed to counter these disadvantages and enable the processing of highly reactive resins such as polyurethanes or amine-curing epoxy systems, which only have short pot lives $[9,10,11]$. These innovative polymer systems have only been used in pultrusion for the last few years $[12,11]$. Due to the high reactivity of these systems, their processing must be carried out using an ii-chamber. Here the components of the resin system are mixed just before processing to prevent premature curing. Furthermore, these newly developed resin systems offer better mechanical properties regarding brittleness and fatigue behavior $[13,14,15]$. The use of new materials opens up a wide field of new potential applications for pultrusion [16].

New challenges for the manufacturing process arise due to the necessity of CIP of these resin systems [8]. Pultrusion with impregnation in an ii-chamber is, therefore, the subject of current research $[17,18,19,20]$. In a preliminary study, several parameters were identified that have an influence on impregnation and component quality [21]. An ii-chamber that can be configured in different ways was developed for a more detailed investigation of defined influencing parameters [21]. Using this developed ii-chamber, a simple modification of individual processing parameters can be performed, and the influence of specific parameter variations can be analyzed.

This study aimed to investigate three main parameters influencing the pultrusion process: the opening angle, the injection height and position of a conical ii-chamber as well as the resin viscosity. The investigation was performed by varying individual process parameters in the test setup. To identify the influence of the varied parameters, an analysis strategy was developed to determine the material properties of the laminates produced in the trials. The dependencies 
of the process parameters were demonstrated by evaluating the results. The experimental work was divided into two phases. The first phase included preliminary trials, in which the developed pultrusion die system and the strategy for the materials' scientific characterization were evaluated. A commercially available, petro-based, aliphatic PU pultrusion resin system was used. In the second phase of the study, the predominantly bio-based aliphatic PU-resin system developed in a current, publicly funded research project [22] was used.

\section{Method}

\subsection{Experimental setup}

The closed pultrusion process with ii-chamber has already been examined in respect of its main influencing parameters in a study preceding this work [23]. In it

- the opening angle of the conical ii-chamber,

- the injection height and position and

- the resin viscosity

were identified. In the developed concept, the viscosity can be influenced by tempering the ii-chamber, depending on the material characteristics, within defined limits.

From this study, an ii-chamber concept was derived, which allows easy variation of the identified main influencing parameters. The variable ii-chamber concept comprises a jacket-ii-chamber and inserts. The jacket-ii-chamber design ensures the impregnation unit can be mounted relative to the pultrusion die, ensures leak-tightness, ensures that the process forces that occur can be absorbed, and enables integration of measuring sensors. The inserts allow the geometry to be adapted with regard to the opening angle and injection position. The basic structure of the concept is shown in Fig. 2. The ii-chamber consists of a steel jacket (a) in which different inserts (b) can be mounted. This allows easy variation of multiple geometry parameters. The ii-chamber has a pressure transducer (c), while two further pressure transducers are included in the pultrusion die $(d, e)$. 


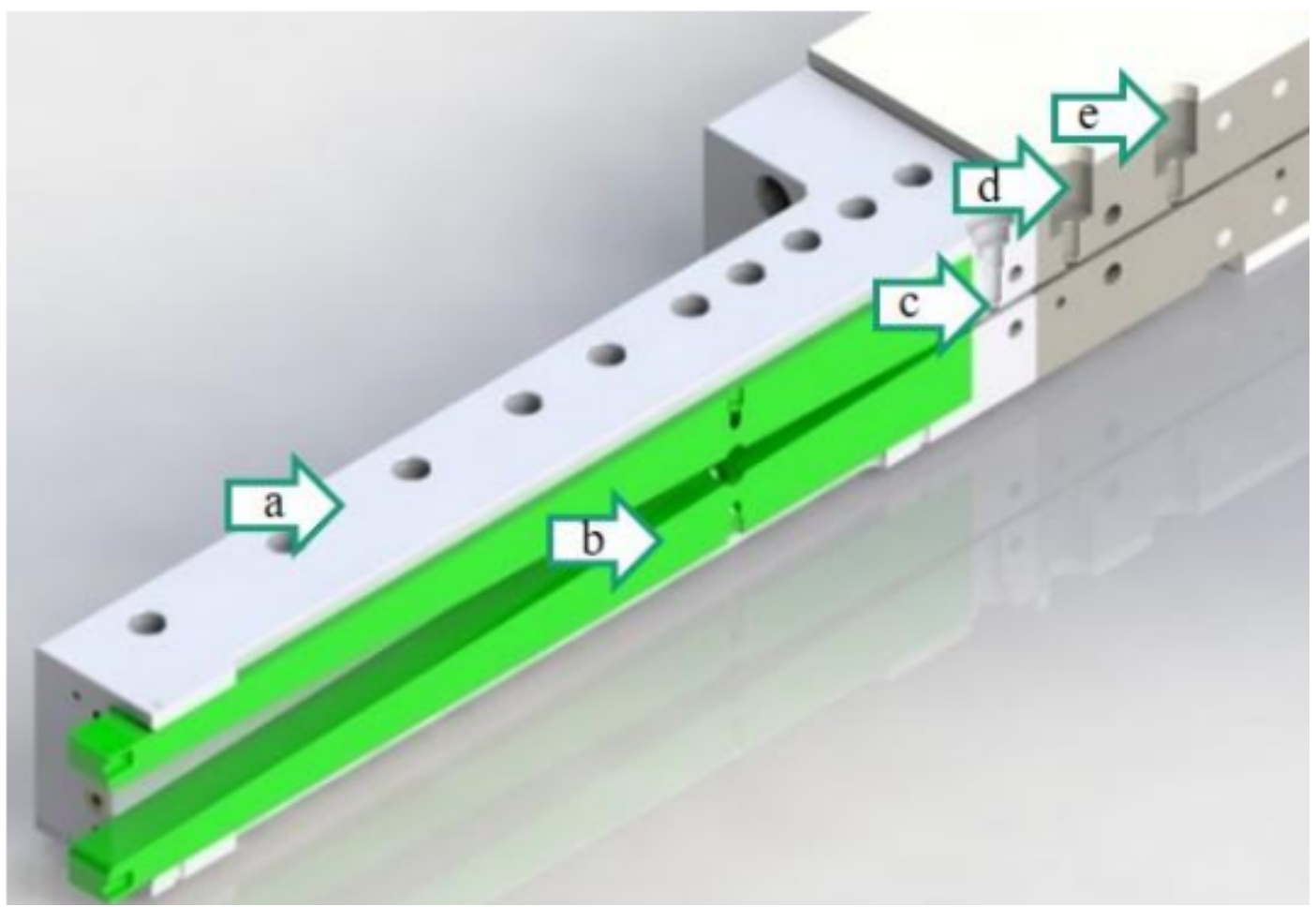

Figure 2: ii-chamber and pultrusion die

The geometric relationships of the ii-chamber are shown in Fig. 3. With the help of the inserts, a variation of the opening angle $\alpha$ as well as the opening factor $Z$ at the injection point (IP) can be achieved. The opening factor $Z$ represents the ratio of injection height $h_{-} I P$ to profile thickness $h_{-}$profile.

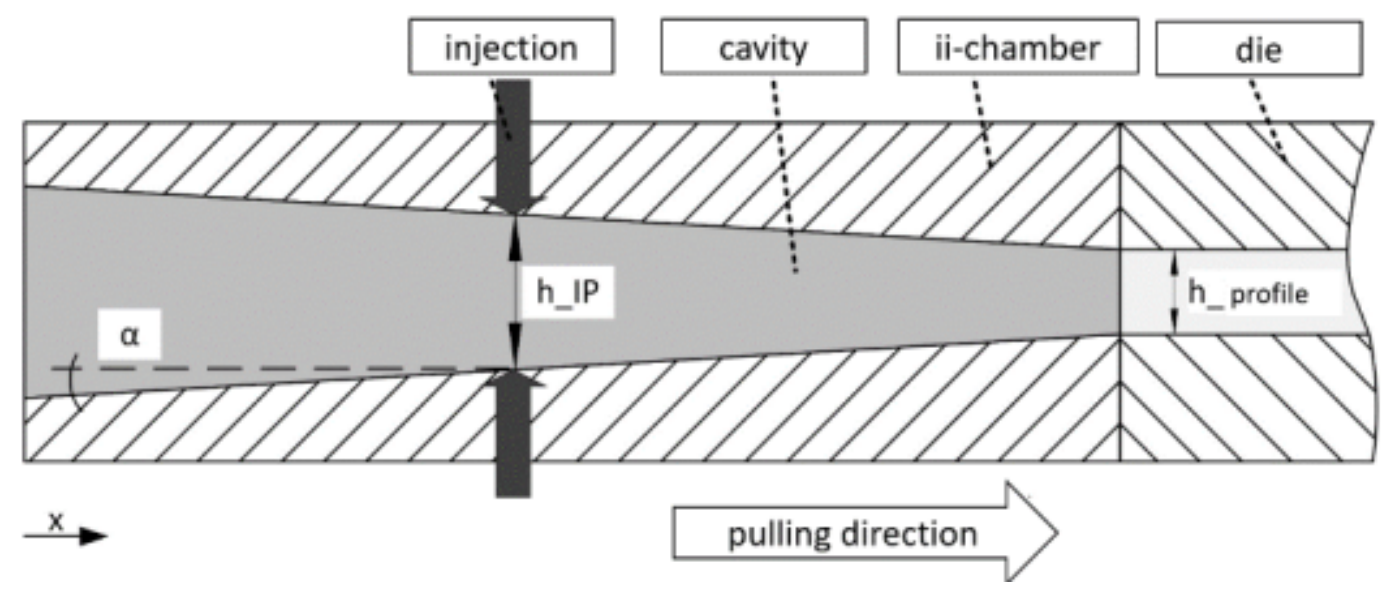

Figure 3: Geometry of the ii-chamber [21]

The trial setup of the pultrusion experiments is shown in Fig. 4. The ii-chamber (2) is connected to the pultrusion die (3), in which the polymerization of the resin takes place. The used pultrusion die is designed to produce flat profiles with a cross-section of $4 \times 60 \mathrm{~mm}^{2}$. The glass fibers used are stored in a creel (1) from which they are continuously drawn off. The resin system is fed using a pneumatically operated pressure pot (5). The resin is injected with a pressure 
of 2 bar inside the pressure pot. The resin can be tempered by hose heaters (6) by which means the resin viscosity can be varied. To ensure constant temperature during impregnation, the ii-chamber has an internal water temperature control (9). To avoid heating the ii-chamber resulting from contact with the heated die, drilled holes for water cooling are integrated into both components around the contact points transverse to the pultrusion process direction.

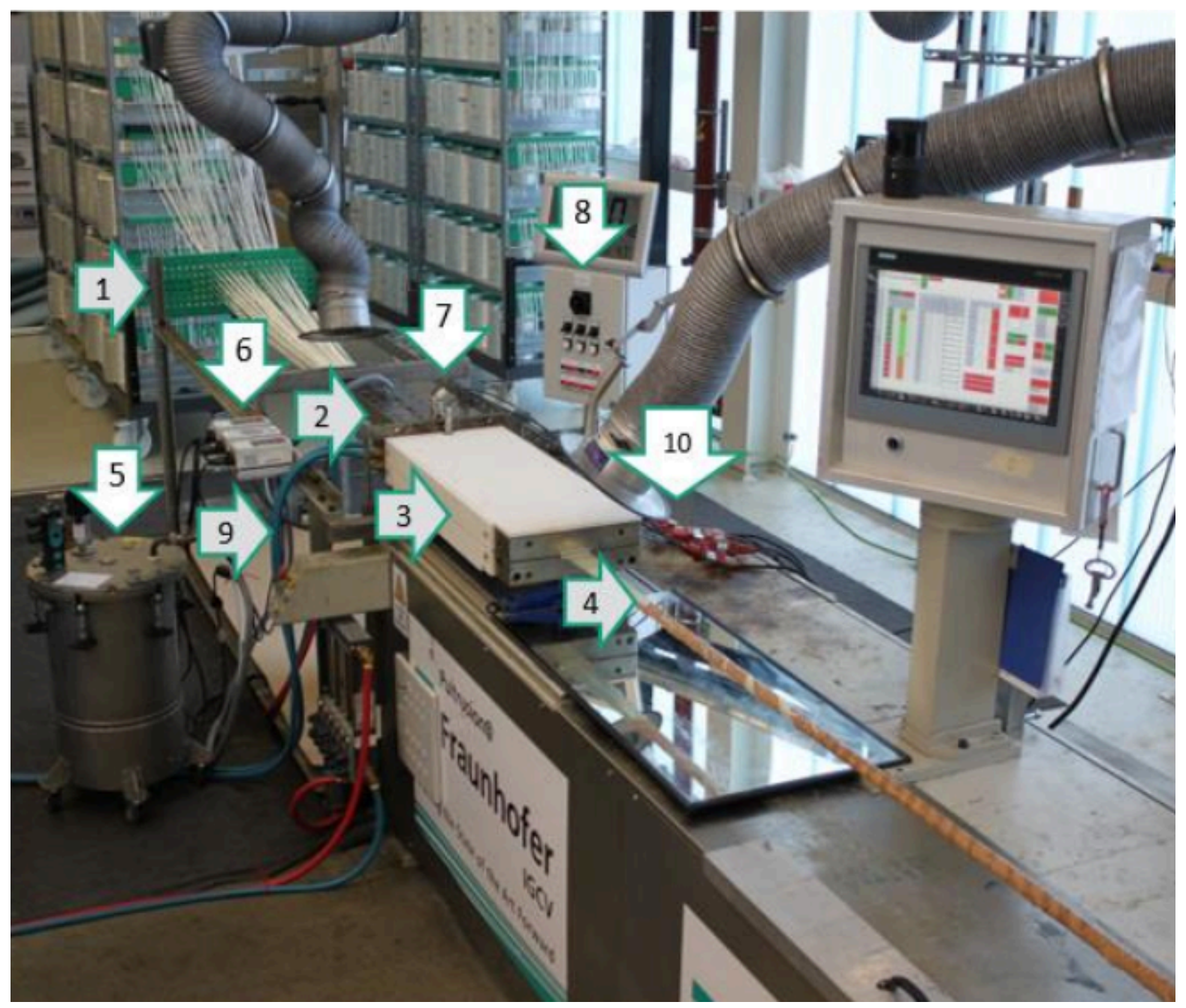

Figure 4: Components of the experimental setup

Three pressure transducers are used to record the pressures generated in the ii-chamber, and pultrusion die during impregnation and curing. Two are positioned in the first third of the die $(25 \mathrm{~mm}$ and $100 \mathrm{~mm}$ to the dividing line between the ii-chamber and pultrusion die). One is positioned in the ii-chamber's parallel end area (-30 mm relative to the dividing line). A caterpillar haul-off unit ensures a continuous pull-off movement, which pulls off the fiber strand (4) and the cured laminate. The experiments can be carried out on an industrial scale using the system described here, and therefore this represents an application-oriented scenario.

The speed of the pultrusion line is set at $0.3 \mathrm{~m} / \mathrm{min}$. In pultrusion, the temperature for polymerization of the resin system must be selected as a function of the line speed. According to the manufacturer's specifications [24], the required die temperature for curing the resin system at line speeds of $0.3 \mathrm{~m} / \mathrm{min}$ is $160{ }^{\circ} \mathrm{C}$. The temperature is generated by electrical heating cartridges integrated into the pultrusion die, see Fig. 4 (10). 
Analysis of the mechanical composite properties of ii-chamber variations in the closed ...

\subsection{Material}

The experiments carried out in this study were divided into two phases. In the first phase, the selected experimental setup and strategy were validated and represented the preparatory work for phase two. A commercially available resin system was used for the preliminary tests: Desmocomp® Ultra, an aliphatic polyurethane based on petrochemical raw materials from Covestro Deutschland AG, see Tab. 1. This system is referred to as the "Petro system" in the following.

For the phase two experiments, a resin system similar to the Petro system was used. This is an innovative resin system developed by Covestro Deutschland AG within the research project PULaCell [25, 26]. The special feature of this system is that it is primarily based on bio-based raw materials. The development work of this resin system for pultrusion has already been presented [27]. The resin system's viscosity is adjusted using partly bio-based, acrylate-based reactive thinners to a level that can be processed in pultrusion. The resin system is referred to as the "Bio system" in the following.

Table 1. Components of the Petro system [24]

\begin{tabular}{llc}
\hline Component & Name & Proportion [wt. \%] \\
\hline Resin & Desmocomp® Ultra AP 200 & 94.8 \\
\hline Catalyst & Desmorapid AP 400 & 1.2 \\
\hline Internal mold release & Desmorapid AP 300 & 4.0 \\
\hline
\end{tabular}

Glass fibers manufactured by OwensCorning are used to reinforce the matrix, which is recommended for processing in pultrusion. The glass fibers used are Pulstrand ${ }^{\text {TM }} 4100$ Type 30 single-end rovings with a fineness of 4800 Tex [28]. Ninety-two rovings are used to achieve the aim for fiber volume content of $68 \%$.

\subsection{Experimental strategy}

The developed test setup makes it possible to achieve different combinations of main influencing parameters to characterize the resulting material properties. In the study presented here, the three main influencing parameters are varied in up to three predefined specifications:

- the opening angle of the ii-chamber $(\alpha)$

- the opening factor of the ii-chamber at injection point $(\mathrm{Z})$

- the Resin viscosity $(\eta)$

An overview of the investigated configurations is given in Tab. 2. The selection of the characteristics of the examined main influencing parameters is described in [21]. The viscosities are each varied in three steps; the indices P and B correspond to the Petro (index: P) and the Bio System (index: B), respectively. Furthermore, the indices denote the pre-temperature stages of $20^{\circ} \mathrm{C}$ (index: 1 ), $40{ }^{\circ} \mathrm{C}$ (index: 2 ), and $60^{\circ} \mathrm{C}$ (index: 3 ) of the ii-chamber and the resin supply line for adjusting the viscosity. The extent of the tests in phase one (dark grey fields of the table) is reduced compared to the full factorial experimental design in phase two, see Tab. 2. The resin viscosities were varied for the tests, and the corresponding temperature levels of $20^{\circ} \mathrm{C}, 40^{\circ} \mathrm{C}$, and $60^{\circ} \mathrm{C}$ for preheating the setup and the resin are summarized in Tab. 3.

Table 2. Overview on the used combinations of process parameters 


\begin{tabular}{|c|c|c|c|c|}
\hline & \multicolumn{4}{|c|}{$\alpha$} \\
\hline \multirow{10}{*}{$\mathbf{Z}$} & \multirow{4}{*}{3} & $1.2^{\circ}$ & $1.6^{\circ}$ & $2.0^{\circ}$ \\
\hline & & $\eta_{1 \mathrm{~B}}$ & $\eta_{1 \mathrm{~B}} ; \eta_{1 \mathrm{P}}$ & $\eta_{1 B}$ \\
\hline & & $\eta_{2 B}$ & $\eta_{2 \mathrm{~B}} ; \eta_{2 \mathrm{P}}$ & $\eta_{2 B}$ \\
\hline & & $\eta_{3 \mathrm{~B}}$ & $\eta_{3 \mathrm{~B}} ; \eta_{3 \mathrm{P}}$ & $\eta_{3 B}$ \\
\hline & \multirow{3}{*}{4} & $\eta_{1 \mathrm{~B} ;} \eta_{1 \mathrm{P}}$ & $\eta_{1 \mathrm{~B} ;} \eta_{1 \mathrm{P}}$ & $\eta_{1 \mathrm{~B} ;} \eta_{1 \mathrm{P}}$ \\
\hline & & $\eta_{2 \mathrm{~B}} ; \eta_{2 \mathrm{P}}$ & $\eta_{2 \mathrm{~B}} ; \eta_{2 \mathrm{P}}$ & $\eta_{2 \mathrm{~B} ;} \eta_{2 \mathrm{P}}$ \\
\hline & & $\eta_{3 \mathrm{~B}} ; \eta_{3 \mathrm{P}}$ & $\eta_{3 \mathrm{~B}} ; \eta_{3 \mathrm{P}}$ & $\eta_{3 \mathrm{~B} ;} ; \eta_{3 \mathrm{P}}$ \\
\hline & \multirow{3}{*}{5} & $\eta_{1 \mathrm{~B}}$ & $\eta_{1 \mathrm{~B} ;} \eta_{1 \mathrm{P}}$ & $\eta_{1 \mathrm{~B}}$ \\
\hline & & $\eta_{2 B}$ & $\eta_{2 \mathrm{~B}} ; \eta_{2 \mathrm{P}}$ & $\eta_{2 B}$ \\
\hline & & $\eta_{3 B}$ & $\eta_{3 \mathrm{~B}} ; \eta_{3 \mathrm{P}}$ & $\eta_{3 B}$ \\
\hline
\end{tabular}

Table 3. Overview of viscosities and temperatures of the resin $\left(1: 20^{\circ} \mathrm{C}, 2: 40^{\circ} \mathrm{C}, 3: 60^{\circ} \mathrm{C}\right)$

\begin{tabular}{cccc} 
& Temperature & Petro system & Bio system \\
\hline$\eta_{1}$ & $20^{\circ} \mathrm{C}$ & $1678 \mathrm{mPa} \cdot \mathrm{s}$ & $1213 \mathrm{mPa} \cdot \mathrm{s}$ \\
\hline$\eta_{2}$ & $40^{\circ} \mathrm{C}$ & $475 \mathrm{mPa} \cdot \mathrm{s}$ & $338 \mathrm{mPa} \cdot \mathrm{s}$ \\
\hline$\eta_{3}$ & $60^{\circ} \mathrm{C}$ & $167 \mathrm{mPa} \cdot \mathrm{s}$ & $124 \mathrm{mPa} \cdot \mathrm{s}$ \\
\hline
\end{tabular}

\subsection{Material characterization}

After the tests have been carried out, the manufactured laminates are mechanically tested. Based on the results obtained, conclusions are reached regarding the influence of parameter variations on the laminates' mechanical properties. The test methods used are based on comparable studies [29, 30, 31, 32] and include the determination of the bending properties in $0^{\circ}$ and $90^{\circ}$ orientations as well as the apparent ILSS in short beam bending tests.

The method of determination of the bending properties is specified in DIN EN ISO 14125 [33]. This includes the threepoint bending test $\left(90^{\circ}\right)$ and the four-point bending test $\left(0^{\circ}\right)$. Since the dimensions of the pultrudates are limited by the geometry of the pultrusion die, the $90^{\circ}$ bending properties are determined by the standard, see Tab. 4 . Therefore, a comparison of the values is only possible within this study. The determination of the ILSS is intended to provide an assessment of the fiber-matrix interaction as well. The ILSS test was performed in accordance with DIN EN ISO 14130 [34], see Tab. 4.

Table 4. Specimen dimensions [33] [34] 
Analysis of the mechanical composite properties of ii-chamber variations in the closed ...

\begin{tabular}{|llllll}
\hline Method & Length $[\mathrm{mm}]$ & Width $[\mathrm{mm}]$ & Height $[\mathrm{mm}]$ & Support distance $[\mathrm{mm}]$ & Fiber orientation $\left[{ }^{\circ}\right]$ \\
\hline Three-point bending test & 60 & 15 & 4 & 40 & 90 \\
\hline Four-point bending test & 120 & 15 & 4 & $30 ; 90$ & 0 \\
\hline ILSS & 40 & 20 & 4 & 20 & 0 \\
\hline
\end{tabular}

\section{Results and Discussion}

To analyze the influence of the individual parameter variations, tests have been conducted in two phases. In the first phase, the experimental field was limited to 15 parameter combinations. The material investigations were carried out on the pultruded composites. In addition, an OB reference test at room temperature was carried out. The composites produced in this way were also analyzed in respect of their material properties using the presented methodology.

The flexural strength measured in the $90^{\circ}$-three-point and $0^{\circ}$-four-point flexural tests does not differ significantly within the two test methods, as shown by the results. An influence on the flexural strength in $0^{\circ}$ and $90^{\circ}$ orientation cannot be identified in the comparison within the CIP test series. Likewise, the values of the $0^{\circ}$ - and $90^{\circ}$-flexural strength of $\mathrm{OB}$ impregnation and impregnation via CIP for the investigated petro-based resin system are within the respective standard deviations. A significant influence of the two different impregnation variants cannot be identified in the present test series for either analysis method. Therefore, it is assumed that the variation of the investigated main influencing parameters has no influence on the flexural strength. Consequently, no determination of the bending properties is performed for the Bio system composites in phase two.

The results from the ILSS tests, on the other hand, show clearly identifiable effects. The determined apparent ILSS with the corresponding standard deviations are shown in Figure 5. The tests performed with the Petro systems and their parameter configurations are shown on the abscissa. The designation follows the following nomenclature: Opening angle_opening factor_resin temperature_test number. The individual parameter configurations can also be found in Tab. 2.

Looking at the ILSS values, a dependence on the resin viscosity becomes apparent. Lower resin viscosities during the impregnation of the fibers tend to lead to higher values of apparent ILSS ( $\tau$ ). With one exception (test series 66), this tendency can be seen in all tests. On the other hand, varying the opening angle and factor does not seem to have any discernible effect. It is possible that too small differences within the various parameter ranges were chosen for the tests. The highest ILSS values for the carried out phase one is $65.38 \mathrm{MPa}\left(\mathrm{Z}: 5 ; \alpha: 1,6^{\circ} ; \eta 3 \mathrm{P}: 167 \mathrm{mPa} \cdot \mathrm{s}\right)$. The lowest ILSS value within the test series was $58.24 \mathrm{MPa}\left(\mathrm{Z}: 4 ; \alpha: 1^{\circ} 2^{\circ}\right.$; $\left.3 \mathrm{P}: 1678 \mathrm{mPa} \cdot \mathrm{s}\right)$. The reference test with impregnation in an $\mathrm{OB}$ is in the lower middle range of the measurement results and achieved an apparent ILSS of $60.03 \mathrm{MPa}$. In more than $60 \%$ of the conducted test series, a trend of decreasing ILSS with increasing viscosity when impregnated with CIP can be seen, see Fig. 5 (test series with trend arrow). 


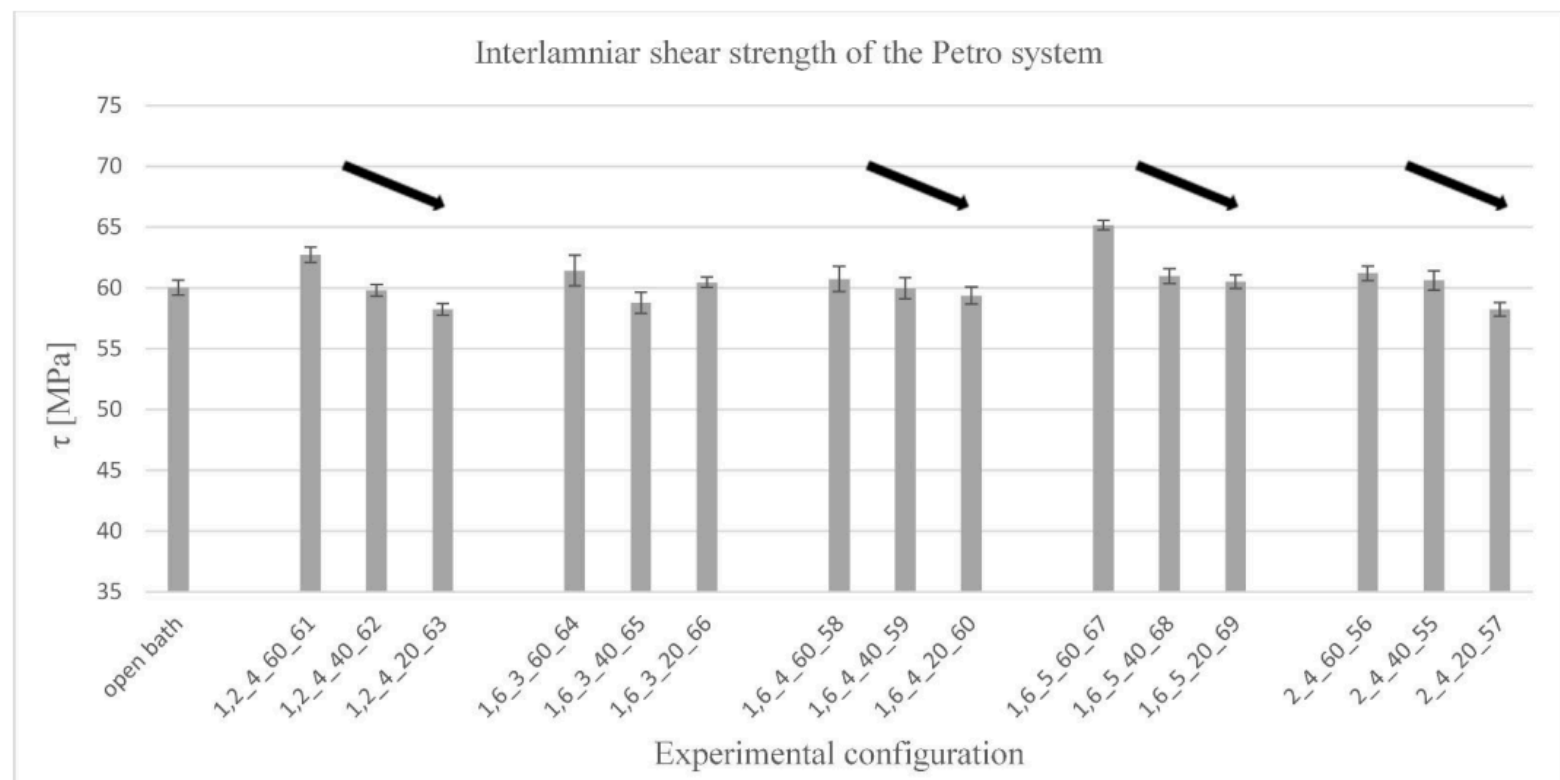

Figure 5:Determination of the apparent ILSS (Petro system). Nomenclature: opening angle_opening factor_resin temperature_test number

In phase two, the test field was extended by further parameter combinations, see Tab. 2. The material properties of the composites from the Bio system experiments were characterized only by ILSS values, see Fig. 6 . The figure shows the test series sorted first by opening angle, then by opening factor. Within the test series, there is a clustering according to viscosity. The nomenclature of the test designation is the same as that used in Fig. 5.

The results obtained with the Bio system in phase two differ from those of the Petro system. Although a dependency of ILSS on resin viscosity is also apparent, it is not as explicit. In contrast to the Petro system, the ILSS values increase with increasing resin viscosity in about half of the experiments. As with the work in phase one, no uniform influence of the opening angle and opening factor can be identified within these experiments. The standard deviations determined in the tests are significantly larger than in phase one, which makes it considerably more challenging to interpret the results. In four out of nine test series, the trend of increasing ILSS values with increasing viscosity can be seen, see Fig. 6 (straight arrows). One third of the test series show a maximum of the ILSS values in the range of the average viscosity values, see Fig. 6 (curved arrows). The selected illustration allows clear evaluation based on the primary influence of the resin viscosity. Similarly, representations with the primary assignment according to one of the other two main influencing parameters are also possible. Again, no trends valid across all test series can be visualized here either. This indicates that at least one other effect in the bio-based system influences ILSS values, but which cannot be shown with the study conducted here. 


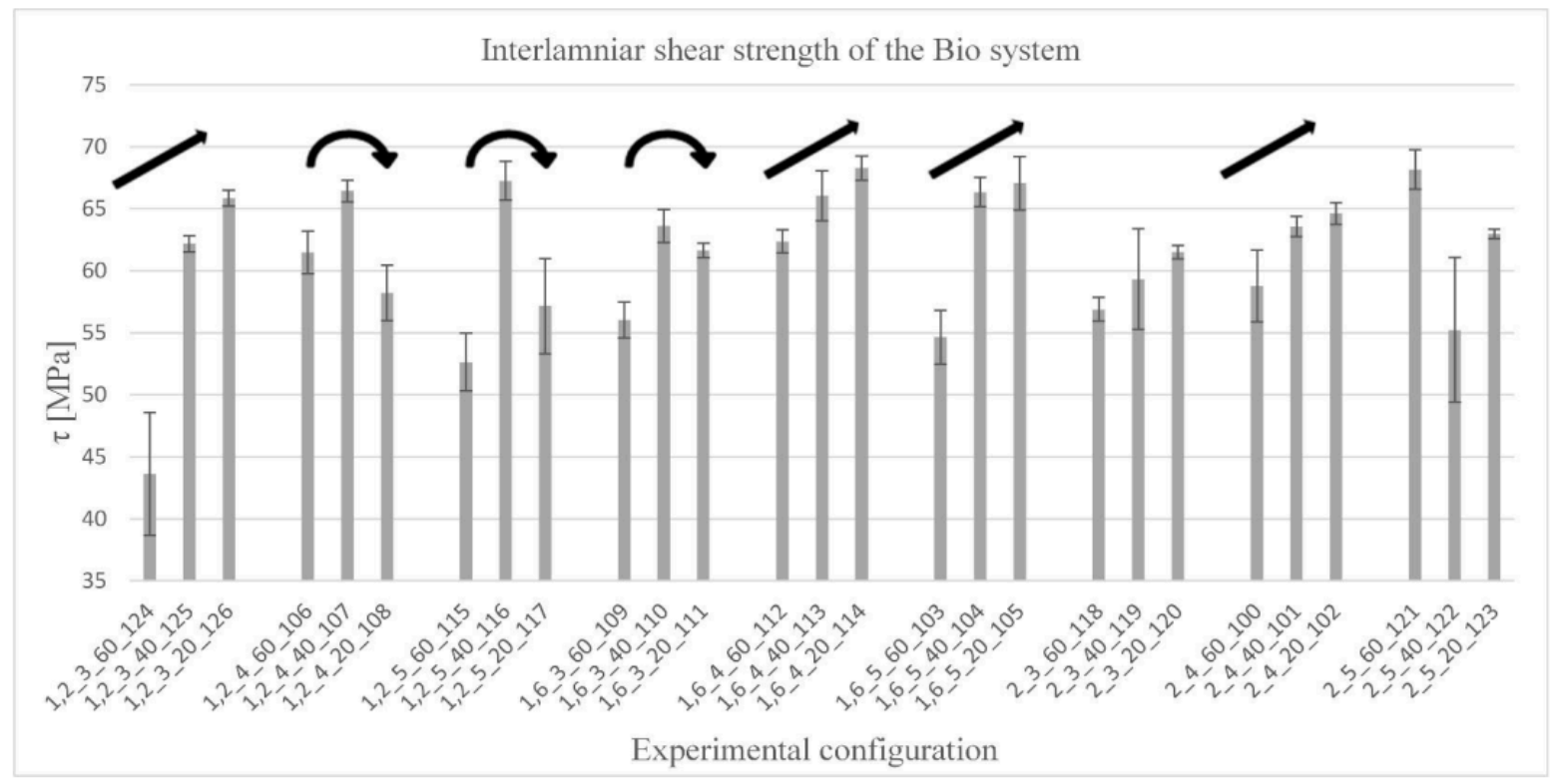

Figure 6: Determination of the apparent ILSS (Bio system). Nomenclature: opening angle_opening factor_resin temperature_test number

\section{Conclusion}

Within the scope of the present study, a strategy for the systematic variation of the main influencing parameters relevant for pultrusion was experimentally validated. Using selected parameter variations, their influence on the laminate quality was investigated. For the evaluation of the laminate quality, a selection of material science test methods was defined. The validation tests were performed in two phases. Phase one served to check the test setup and the selected mechanical material testing methods. In phase two, the analysis strategy was adapted based on the knowledge gained. In phase two, an enlarged range of combinations of the main influencing parameters in the pultrusion process was analyzed.

The investigation of the mechanical characteristics from phase one did not show an identifiable influence of the parameter variations on the flexural strengths in $0^{\circ}$ and $90^{\circ}$ fiber orientation. It was also shown that the flexural strength for the investigated materials is independent of the impregnation mechanism (OB or CIP) as well as of the characteristics of the analyzed parameters of $\operatorname{CIP}(\eta, \alpha, Z)$. The composites' flexural strength is of the same order irrespective of the selected impregnation method CIP or OB.

On the other hand, materials testing of the apparent ILSS revealed a clear influence of resin viscosity on the laminate quality. The influence depends on the resin system used and cannot be described in a generally applicable manner. The variation of the resin viscosity indicates different trends in the two resin systems considered. A more in-depth examination of all the varied parameters' mutual interactions would appear to be a useful extension of the analysis to uncover any existing sensitivities.

In general, the test setup used in this study can be considered suitable for investigating the influence of process parameter variations on different resin systems. Relying on this setup, individual parameters can be easily, quickly, and cost-effectively varied and then examined regarding their influence using material tests. Based on the setup used, an evaluation of the optimal processing parameters for different resin systems can be made. 


\section{Acknowledgments}

The work has been conducted as part of the PULaCell research project funded by the Agency for Renewable Resources (FNR) on behalf of the Federal Ministry of Food and Agriculture (BMEL) based on a decision of the German Bundestag. The Hanns-Seidel-Foundation funded the publication as part of a scholarship.

\section{Bibliography}

[1] T. Starr. Pultrusion for engineers. Abington: Woodhead, 2000.

[2] K. G. Swift, J. D. Booker. Manufacturing process selection handbook. Oxford (U.K.), 2013.

[3] R. W. Meyer. Handbook of Pultrusion Technology. London: Chapman and Hall, 1985.

[4] J. Fleischer, G. Lanza, P. T. Mativenga, H.-C. Möhring, R. Teti, A. Caggiano. Composite Materials Parts Manufacturing. 1st CIRP Conference on Composite Materials Parts Manufacturing, 2017.

[5] M. Bannister. Challenges for composites into the next millenium - a reinforcement perspective. Composites Part A, 32(7):901-910, 2001.

[6] H. Engelen. Pultrusion mit duromeren Harzsystemen. Sika Composite Customer Day, München. 2018.

[7] Z. Ding, S. Li, H. Yang, L. James Lee, H. Engelen, P. M. Puckett. Numerical and experimental analysis of resin flow and cure in resin injection pultrusion (RIP). Polymer Composites, pp. 21(5):762-778, 2000.

[8] S. Voorakaranam, B. Jospeh, J. L. Kardos. Modeling and Control of an injection pultrusion process. Journal of Composite Materials, p. 33(13):1173-1204, 1999.

[9] S. Strauß. Flexibility in Polyurethane Injection Molding. North American Pultrusion Conference, Chicago, 2019.

[10] H. Engelen, Development and comparison of resin injection and impregnation chambers for pultrusion. World Pultrusion Conference, Istanbul, Turkey, 2012.

[11] M. G. Dubé, G. L. Batch, J. G. Vogel, C. W. Macosko. Reaction Injection Pultrusion of Thermoplastic and Thermoset Composites. Polymer Composites, p. 378-385, 1995.

[12] C.-H. Chen, C.-C. M. Ma. Pultruded fiber reinforced blocked polyurethane (PU) composites. Journal of Applied Polymer Science, pp. 466 937-947, 1992.

[13] W. Michaeli, T. Preuss. Polyurethan - Pultrusion von faserverstärkten Kunststoffprofilen. Lightweight Design, p. 3(5):59-65, 2010.

[14] M. Conolly, J. King, T. Shidaker, A. Duncan, Pultruding Polyurethane Composite Profiles: Practical Guidelines for Injection Box Design, Component Metering and Processing, Auburn Hills: Huntsman International LLC, 2005.

[15] S. Mentizi. Composite solutions from Covestro. UTECH Europe 2018, 2018.

[16] S. Strauß, F. Wilhelm. Current Pultrusion Research Topics. World Pultrusion Confernce, 2018.

[17] R. Bezerra. Modeling and Simulation of the Closed Injection Putrusion. Dissertation, 2017.

[18] F. Wilhelm, S. Strauß, M. Kronseder. Influence of power ultrasonic on the viscosity of epoxy resin. Result in 
Analysis of the mechanical composite properties of ii-chamber variations in the closed ...

Materials, 2020.

[19] C. Hopmann, P. Schneider, A. Böttcher. Von der Injektionsbox zum komplexen Werkzeug zur Fertigung von Hybridprofilen. Konstruktion, p. (7/8):6-9, 2015.

[20] D. Krebs. Grundlagen der Pultrusion zur Fertigung von FV-Bauteilen für die Anforderungen der automobilen Großserie. Dissertation, 2018.

[21] S. Strauß, F. Wilhelm. Development of a flexible injection and impregnation chamber for pultrusion of high reactive resin. Procedia Manufacturing, p. 956-961, 2020.

[22] P. Heinz. Vorhabensbeschreibung PULaCell - Biobasierte Polyurethan Verstärkungslamelle mit Cellulosefasern für Holzkonstruktionen, 2018.

[23] S. Strauß. Development of a flexible injection and impregnation chamber for pultrusion of high reactive resins. International Conference on Material Forming, virtuell conference, 2020.

[24] Covestro Deutschland AG. Desmocomp® Ultra - Raw Material preparation for pultruded composites, Leverkusen: Covestro Deutschland AG, 2019.

[25] S. Mentizi, A. Hecking, S. Strauß, D. Achten, M. A. Guiteras. Aliphatic Polyurethanr Matrix for more sustainable UV-Resistant Composites. Revista de la Asociación Espanola de Materiales Compuestos, pp. 28-31, 2019.

[26] Covestro Deutschland AG. Composites materials based on dual-curing isocyanurate polymers, Leverkusen: Covestro Deutschland AG, 2018.

[27] S. Strauß, R. Meisenheimer, A. Hecking, A. Senz, F. Wilhelm. Manufacturing of predominantly bio-based composite profiles with pultrusion. International Conference on Composite Materials, Melbourne, 2019.

[28] OwnsCorning Composite Materials LLC. Pulstrand 4100 Single-End Roving. OwnsCorning Composite Materials LLC, 2015.

[29] W. Michaeli. Pultrusion of Composite Profiles - Polyurethane (PU) as Alternative Matrix System, Polymers and Polymer Composites. 18(9): 537-542, 2010.

[30] G. Bramante, L. Bertucelli, A. Benvenutti, J. Meyer-K. Polyurethan Verbundstoffe: Mechanische Analyse von pultrudierten Laminaten: Eine vielseitige Duroplast-Polymermatrix für eine Vielzahl von Anwendungen. PU Magazin. 15(3): 136-145, 2015.

[31] C.-C. M. Ma, D. Y. Goang, J. L. Han, K. H. Hsieh. Interpenetrating polymer networks of polyurethane and furfuryl alcohol: II a. Processability and properties of pultrudet fiber-reinforced composites. Angewandte Makromolekulare Chemie, 218(1): 41-52, 1994.

[32] D. J. Jaklitsch, M. T. Bostic, E. R. Pattie. An examination of processing variables in the pultrusion of glass reinforcements with an epoxy-anhydrite resin system. Watertown: U.S. Army Materials Technology Laboratory, 1991.

[33] Deutsches Institut für Normung e.V. DIN EN ISO 14125, Berlin: Beuth Verlag GmbH, 2011.

[34] Deutsches Institut für Normung e.V. DIN EN ISO 14130, Berlin: Beuth Verlag GmbH, 1998. 
Article url: https://popups.uliege.be/esaform21/index.php?id=970

published by ULiège Library in Open Access under the terms and conditions of the CC-BY License (https://creativecommons.org/licenses/by/4.0) 